\title{
Using structural equation modelling to integrate human resources with internal practices for lean manufacturing implementation
}

\author{
Protik Basu $^{\mathrm{a}^{*}}$, Indranil Ghosh ${ }^{\mathrm{b}}$ and Pranab K. Dan
}

${ }^{a}$ Army Institute of Management, Judges Court Road, Alipore, Kolkata - 700027, India

${ }^{b}$ Calcutta Business School, Diamond Harbour Road, 24 Parganas South, West Bengal - 743503, India ${ }^{c}$ Rajendra Mishra School of Engineering Entrepreneurship, Indian Institute of Technology, Kharagpur, India

CHRON I CLE A B S TRACT

Article history:

Received: July 24, 2017

Received in revised format: $\mathrm{Au}-$ gust 6, 2017

Accepted: October 25, 2017

Available online:

October 26, 2017

Keywords:

Lean manufacturing

Lean implementation

HR practices

Internal manufacturing practices

Lean benefits

Structural model

\begin{abstract}
The purpose of this paper is to explore and integrate the role of human resources with the internal practices of the Indian manufacturing industries towards successful implementation of lean manufacturing (LM). An extensive literature survey is carried out. An attempt is made to build an exhaustive list of all the input manifests related to human resources and internal practices necessary for LM implementation, coupled with a similar exhaustive list of the benefits accrued from its successful implementation. A structural model is thus conceptualized, which is empirically validated based on the data from the Indian manufacturing sector. Hardly any survey based empirical study in India has been found to integrate human resources with the internal processes towards successful LM implementation. This empirical research is thus carried out in the Indian manufacturing industries. The analysis reveals six key input constructs and three output constructs, indicating that these constructs should act in unison to maximize the benefits of implementing lean. The structural model presented in this paper may be treated as a guide to integrate human resources with internal practices to successfully implement lean, leading to an optimum utilization of resources. This work is one of the very first researches to have a survey-based empirical analysis of the role of human resources and internal practices of the Indian manufacturing sector towards an effective lean implementation.
\end{abstract}

\section{Introduction}

Lean management is an integrated socio-technical system to bring about a competitive state in an organization. In the recent years, Lean Manufacturing (LM) is gaining considerable importance (Shah et al, 2008) and popularity as an approach that can achieve considerable performance improvement in the industry (Susilawati et al., 2015). Though the lean concept itself was not a single-point invention but the outcome of a dynamic learning process that adapted practices emanating from the automotive and textile sectors in response to environmental uncertainties in Japan (Holweg, 2007), the term "lean" was coined by Krafcik (1988). In his landmark paper, Krafcik introduced the term "lean" to describe a

\footnotetext{
* Corresponding author. Tel.: +91 9831190934

E-mail address: protik_basu@yahoo.com (P. Basu) 
production system that uses less resources of everything compared to mass production. Derived originally from the Toyota Production System or TPS, the principles, methods and tools of LM became immensely popular after the release of the book 'The Machine that Changed the World' (Womack et al., 1990) and lean practices are no longer culturally bound to Japan; they are indeed transferable to other countries and organisations as well (Holweg, 2007).

While recent articles have demonstrated a growing recognition of the importance of human resources (HR) in implementing lean, little attention has been paid to these (Taylor et al., 2013). Although there have been a few studies for the various aspects of HR in lean implementation, there is no comprehensive study of the same. The purpose of this study is to have a detailed study of the relationship of HR with internal practices for the implementation of lean manufacturing, towards satisfaction of the customer and the organizational objectives, as well. This work entails an empirical research on a model for LM implementation based on profound literature survey. This study provides an insight in a realistic situation in LM implementation where practically all considered input manifests related to HR and internal practices and all considered output manifests have been assimilated to formulate the research problem. Therefore the challenge is to undertake a research combining all the stated manifest variables in a comprehensive manner to gain an insight of a integrated model to provide direction for LM implementation.

In November 2011, the Government of India (GOI) announced a National Manufacturing Policy (NMP) with the observation that the share of manufacturing in India's GDP has stagnated at $15-16 \%$ since 1980 while the share in comparable economies in Asia is much higher at 25-34\% (NMP, 2011). With the current impetus on developing the industrial sector, the GOI recently introduced the 'Lean Manufacturing Competitiveness Scheme' (LMCS) that aims to increase competitiveness with the help of lean concepts (LMCS, 2013). There is a huge scope to enrich the Indian industries with the lean benefits, the implementation status being quite low. There have been a few empirical studies on lean in the Indian manufacturing sector but those have been mostly restricted to a few case studies primarily focussed on assessing the current status of LM. There is hardly any survey based empirical study in India to integrate HR with the internal processes towards successful LM implementation. This empirical research is thus carried out in the Indian manufacturing industries.

The paper is organized as follows. Section 2 discusses the related literature and develops the hypotheses, based on which the research model is established. Section 3 outlines the research methodology and the model validation is carried out in Section 4. Section 5 discusses the theoretical and managerial implications of the results and finally Section 6 concludes the study with a summary, limitations and suggestions for future research.

\section{Literature Review and Hypotheses Development}

Womack et al. (1990) defined lean as the combination of the advantages of craft and mass production, while "avoiding the high cost of the former and the rigidity of the latter." The term "lean" is used to specify that less of everything is being used in lean production and this "everything" includes inventory, human effort, manufacturing space, investment in tools and engineering hours to develop a new product. Lean focuses on perfection in all activities.

\subsection{Literature Review}

This research article is based on a systematic literature review. By a different combination of key words, 418 publications in refereed journals were finally shortlisted for this research work. The target journal articles for this review were those published after 1990 that is, post publication of the book, 'The Machine that Changed the World' (Womack et al., 1990). 
The manufacturing era had started with craft manufacturing. Thereafter, there evolved the age of mass production, where same item was produced in large numbers to take advantage of economies of scale. More recently, there is the emergence of the concept of LM which is gaining popularity as an approach to achieve significant improvements in the industry (Susilawati et al., 2015). In the past few decades much attention has centred on lean and many researchers have contributed to the definition of LM (Vinodh \& Chintha, 2011). Bhamu \&Singh Sangwan (2014) have provided 33 such definitions of lean in a chronological order, "reflecting the changing goals, principles and scope". Being a multi-dimensional concept (Shah \& Ward, 2003), lean includes a variety of management principles and practices under its umbrella and recently rigorous academic research has highlighted a broad set of such practices under LM (Shah et al., 2008) to reduce cost through the persistent removal of waste and through the simplification of all manufacturing and support processes (Kajdan, 2008). Focus is to produce only what is demanded by the customer and only at the necessary time and quantity, thereby eliminating waste and utilizing resources efficiently (Chavez et al., 2015).

Though there have been a few hundreds of papers on lean, there have been no such studies to provide a comprehensive list of all the HR practices along with the internal processes towards successful implementation of LM. This paper is an endeavour to bridge the gap and provide an exhaustive list of the said parameters. From the review of past literature, this study has attempted to embrace both the technical parameters on one hand and the soft skills on the other hand. More specifically, in the context of the Indian manufacturing industries, the present study seeks to have a comprehensive model integrating the human interface with the internal practices for successful lean implementation. This model may be used by academicians and practitioners to effectively execute and administer the lean implementation process.

\subsubsection{Identification of Input Manifest Variables and Latent Constructs related to HR and internal practices}

In the first phase of the research, an intense literature survey revealed eighty six various terminologies related to HR and internal practices as enablers for LM implementation.

\section{Table 1}

Input Manifests and Latent Constructs related to HR and internal practices for LM implementation

\begin{tabular}{ll}
\hline Latent Construct & Manifest Variables / Measures \\
\hline Human Resource Management (HRM) & Workforce Empowerment and Leadership (HRM1) \\
& Training and Cross-Functional Workforce (HRM2) \\
& Teamwork and Problem Solving (HRM3) \\
& Employee Involvement and Satisfaction (HRM4) \\
& Culture of the Organization (HRM5) \\
\hline Integrative Planning and Scheduling (IPS) & Cycle and Lead Time Reduction (IPS1) \\
& Production Smoothing (IPS2) \\
& Time Management and Scheduling (IPS3) \\
\hline Internal Operations Synchronization (IOS) & Work Standardization (IPS4) \\
& Continuous Flow (IOS1) \\
& Pull System (IOS2) \\
& Setup Reduction (IOS3) \\
& Lot Size Reduction and SPF (IOS4) \\
& Total Productive Maintenance (IOS5) \\
\hline Management Role (MR) & Top Management Support (MR1) \\
& Few Levels of Management (MR2) \\
& Vision and Long Term Commitment (MR3) \\
\hline Quality Governance (QG) & Hoshin Kanri (MR4) \\
\hline TQM \& Kaizen (QG1) \\
SPC and Process Capability (QG2) \\
\hline Quality Tools and Techniques (QG3) \\
\hline Quality Practices (QG4) \\
\hline Process and Value Stream Mapping (SPC1) \\
Value Analysis and Waste Elimination (SPC2) \\
\hline Visual Management (SPC3) \\
Equipment Layout and Materials Handling (SPC4) \\
\hline
\end{tabular}


Since all of these 86 items were not distinct in nature, these were verified and based on the similarity of the attributes, combined into 30 manifest variables through a Delphi exercise with seven practitioners and researchers known for their knowledge and experience in lean production. These 30 manifest variables were conceptually mapped onto 6 distinct latent constructs, considering the salient inherent similarities between them. Finally, through an Exploratory Factor Analysis (discussed in Section 4.2 below), these 30 measures were reduced to 26 manifests, grouping of which matched with the 6 latent constructs. The latent constructs and their respective manifest variables are enumerated in Table 1.

\subsubsection{Identification of Output Manifest Variables and Latent Constructs of LM implementation}

Many studies have enumerated the benefits of lean. In the first phase, this study identified 215 various terminologies as output attributes from literature survey. These were again verified and based on the similarity of the attributes, combined into 13 manifest variables through a Delphi exercise with seven lean experts and researchers. The 13 manifest variables are conceptually mapped onto three distinct latent constructs, considering the salient inherent similarities between them. These are: Successful LM Implementation, Organizational Goal Satisfaction and Customer Satisfaction. From past literature, it may be inferred that successful LM implementation will lead to satisfaction of both the customer as well the organizational goals. Exploratory Factor Analysis (discussed in Section 4.2 below), confirms the said conceptual mapping. The latent constructs and their respective manifest variables are enumerated in Table 2.

Table 2

Output Manifests and Latent Constructs of successful LM implementation

\begin{tabular}{cl}
\hline \multicolumn{1}{c}{ Latent Construct } & Manifest Variables / Measures \\
\hline Successful LM Implementation (SLM) & Quality Improvement (SLM1) \\
& Reduction of Defects, Scrap \& Rework (SLM2) \\
& Cycle / Lead Time Reduction (SLM3) \\
& Operational Flexibility and Performance Improvement (SLM4) \\
& Work Ethos and Working Conditions Improvement (SLM5) \\
& Productivity Practices Implementation (SLM6) \\
\hline Organizational Goal Satisfaction & Economic Parameters (OGS1) \\
& Strategic Competitiveness (OGS2) \\
& Cost Reduction \& Efficiency Improvement (OGS3) \\
\hline Customer Satisfaction (CS) & Maximize Customer Value (CS1) \\
& Increased Responsiveness to Demand Change (CS2) \\
& Streamlining Customer Service Functions (CS3) \\
& Perfect Order Fulfillment (CS4) \\
\hline
\end{tabular}

\subsection{Hypotheses Development}

Our study is built on the conceptual foundations of the literature followed by Delphi technique and EFA, on the input and output variables of LM implementation, and combines both to propose the theoretical research model of the study as illustrated in Fig. 1. We begin our discussion on hypothesis by developing the relations between the input and output latent constructs of LM implementation. Based on the model thus proposed, eight hypotheses described below are posited. A self-directed work team (Shah \& Ward, 2003), coupled with a strong committed executive leadership (Ravikumar et al., 2013), is an important requirement for successful lean implementation. Training of workers especially in selfdevelopment and problem solving techniques (Marin-Garcia and Bonavia ad Bonavia, 2015) is an essential aspect of lean in an organization. Team leaders / supervisors need to be trained to become experts in lean principles (Motwani, 2003). 


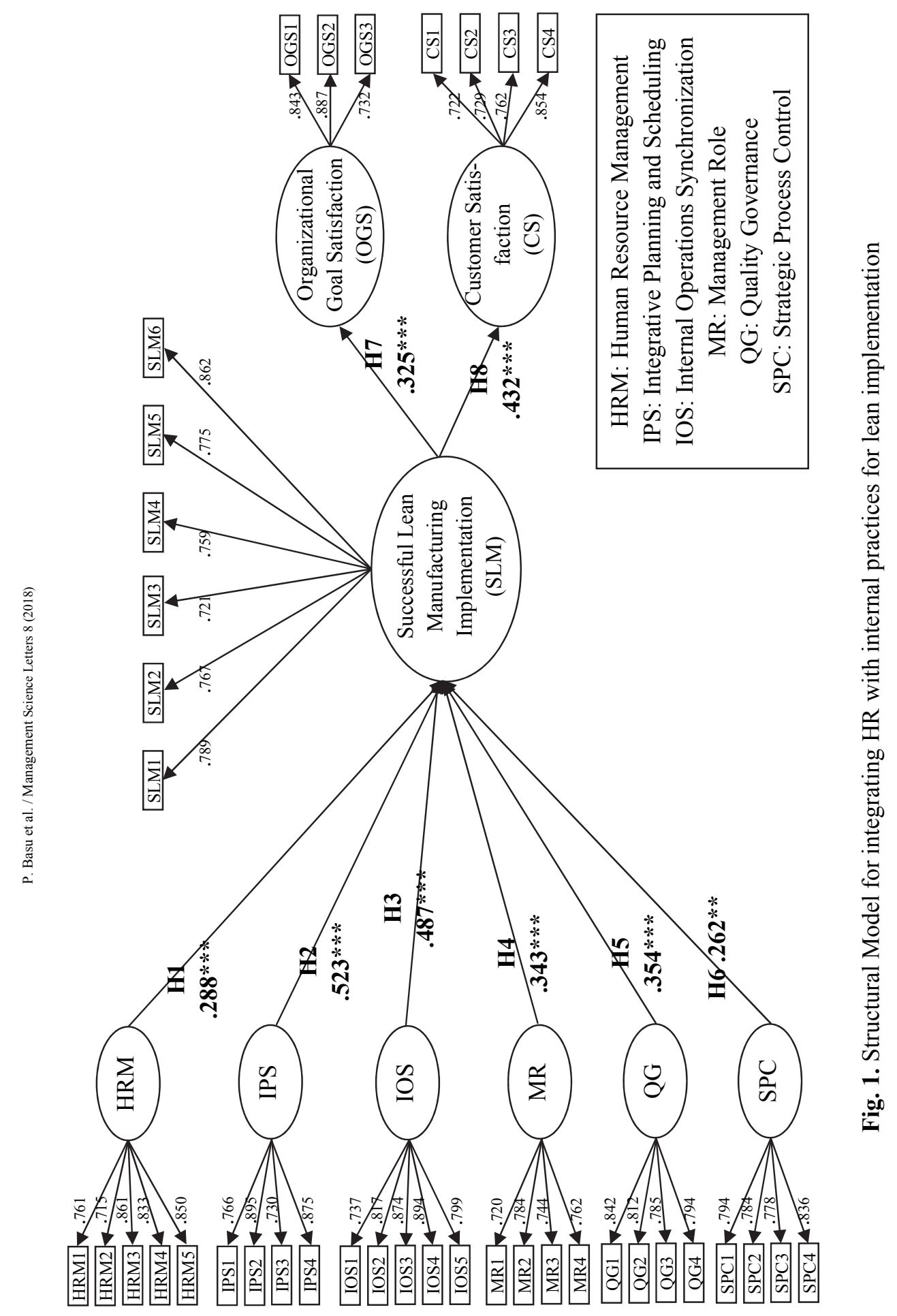


Lean has been distinguished as a bottom-up approach where management plays a supportive and facilitating role in engaging shop-floor workers to form cross-functional work teams and apply lean tools (Shah et al., 2008). During a lean transformation, respect for people is an important principle (Bevilacqua ,2 2015) and is the key to long-term sustainability of any lean programme (Taylor et al., 2013). In lean philosophy, workers need to have sufficient participation (Ravikumar et al., 2013). The level of involvement throughout the organization is one of the important factors in successful lean transformations. Employee satisfaction (Bhasin, 2008) and motivation through innovative performance appraisal and performance related pay systems have been considered as the best practices of HR for a lean enterprise (Panizzolo et al., 2012). In accordance with this discussion, we hypothesize the following:

H1. Human resource management (HRM) is positively related to successful LM implementation.

Shah and Ward (2003) propose that both work-in-process (WIP) inventory and unnecessary delays in flow time can be reduced by cycle time reduction which is considered as one of the lean practices (Doolen \& Hacker, 2005). Lead time reduction is one of the areas lean focuses on to satisfy customers by improving cost, quality and delivery (Liker \& Morgan, 2006). In addition to reduction in cycle time and lead time, Heijunka or production smoothing is a lean concept based on production rhythm monitoring and internalisation (Serrano Lasa et al., 2009). It is a process designed to keep the production level as constant as possible (Abdulmalek et al., 2006). LM stresses on creating a balanced flow in a process (Pakdil \&Leonard, 2014). On the other hand, bottlenecks are system limitations (Serrano Lasa et al., 2009) that choke production (Panizzolo et al., 2012) and hence need to be minimized. The takt time is the heartbeat of a lean system (Deflorin \&Scherrer-Rathje, 2012). It is one of the elements of the JIT bundle, application of which is the key to the success of LM implementation (Begam et al., 2013; Mostafa et al, 2015). Takt time control is a concept that reflects production rate must match the customer requirements (Abdulmalek \& Rajgopal, 2007; McDonald et al., 2002). Lean places strong emphasis on standardization of work (Pettersen, 2009). According to Shetty et al. (2010), process and product standardization is one of LM management strategy. Even TPS includes standardization of work (Haque \& James-Moore, 2004) as its practice. Planning and production scheduling have been considered as an important LM tool (Shah \& Ward, 2003; Susilawati et al., 2015; Upadhye et al., 2010). There have been elaborate discussions on scheduling in LM by Karlsson \& Åhlström (1996) and Sohal et al. (1994). Many authors have focused on mixed model scheduling, synchronized scheduling and undercapacity scheduling (Gurumurthy \& Kodali, 2009; Panizzolo et al., 2012). To examine the direct effects of planning and scheduling in an integrated manner on lean manufacturing implementation, we suggest the following hypothesis:

H2. Integrative planning and scheduling (IPS) is positively related to successful LM implementation.

Extensive literature survey reveals that that JIT/continuous flow production is one of the most frequently mentioned practices in literature on lean manufacturing (Shah \& Ward, 2003) and accordingly, continuous flow and JIT are considered as synonymous in this paper. Continuous flow is a lean manufacturing practice where one establishes mechanisms that enable and ease the incessant flow of products (Cullinane et al., 2014). One of the tenets of lean production is just-in-time inventory systems that create a production process with continuous flow. In conjunction with the continuous flow, the pull system is considered as one of the fundamental LM tools and techniques (Almomani et al., 2013). The term pull is used to imply that nothing is made until it is needed by the downstream customer (Arnheiter \& Maleyeff, 2005). Kanban, an element of the Pull system, is a popular lean tool (Begam et al., 2013; Abdulmalek \& Rajgopal, 2007) that helps the flow in the process as per the requirement of the customer (Zahraee, 2016). In lean production, it is necessary to eliminate delays in change-over times on machines to improve flows (Bhasin \& Burcher, 2006). Setup reduction is a process to reduce such delays in the setup time based on Single Minute Exchange of Dies or SMED (Abdulmalek \& Rajgopal, 2006; Almomani et al., 2013). Lean production emphasizes on production in small batches (Arnheiter \& 
Maleyeff, 2005) with frequent deliveries. In other words, lot size reduction is one of the key approaches to follow to become lean (So \& Sun, 2011). Shah et al. (2008) also considered it to be an element of the lean bundle. A steady flow of materials in small batches allows a faster replenishment of materials, which, in turn, helps to shorten lead time and increase productivity (Wong et al. 2009), as well as, rapidly respond to changes in customer requirements (Almomani et al., 2013). Single Piece Flow is the ultimate ideal of LM (Arnheiter \& Maleyeff, 2005). From the perspective of LM implementation, Total Productive Maintenance or TPM has been considered as an important practice or tool by many researchers, Abdulmalek \& Rajgopal (2007), Green et al. (2010), Salem et al. (2016) and Susilawati et al. (2015), to name a few. In line with the pragmatic concept of continuous flow supported by pull system, setup and lot size reduction and TPM, it is hypothesized that synchronization of internal operations to maintain the flow smoothens the LM implementation process. The next hypothesis is thus framed as:

H3. Internal operations synchronization (IOS) is positively related to successful LM implementation.

Lean is truly a corporate vision (Motwani, 2003). Bhasin \& Burcher (2006) observe that, for effective implementation of lean, there is a need to forward a definite clarity of vision; an indication of what the organisation believes it will look like once the transformation is complete. Lack of a strategic direction and vision of the company towards lean manufacturing could hamper the lean improvement process (Houshmand \& Jamshidnezhad, 2006). This leads to the fact that top management support is not only crucial and important for LM implementation but is also one of the frequently mentioned success factors for LM and is required to approach LM in a systemic or holistic way (Näslund, 2008). Management commitment and support have always been considered critical for lean deployment to reduce wastes, non-value added work and cycle time. Few levels of management had been suggested by Panizzolo et al. (2012) for effective lean implementation. One well-known Japanese management tool is hoshin kanri, also known as policy deployment. This is the process of breaking down high-level corporate goals into meaningful objectives at the working level (Liker and Morgan, 2006). It is the role of management to deploy policies and strategies and to identify key business objectives (Taylor et al., 2013) to align the resources optimally. The above discussions guide us to propose that:

H4. Management role (MR) is positively related to successful LM implementation.

Importance of TQM as a lean practice was postulated by Shah and Ward (2003). Since participative management is a critical ingredient for TQM, TQM principles can be adopted to raise quality consciousness among the workers to decrease rejection due to poor quality and it can help to increase profit (Singh et al., 2009). As an essential feature of lean production, kaizen is the continual pursuit of improvements in quality, cost, delivery and design (Bhasin \& Burcher, 2006). Forza (1996) defines process control as that lean production practice which indicates the "extent of the use of statistical process control (SPC) to maintain control over production processes. In particular it considers how much equipment is under statistical process control and whether charts are widely used." SPC is a lean production practice dedicated to the reduction of variability. Shah and Ward (2007) consider SPC as a distinct dimension of a lean system to ensure that each process supplies defect free units to subsequent processes. Quality management practices in lean production emphasize the concept of zero quality control (ZQC) which includes poka-yoke (Arnheiter \& Maleyeff, 2005). Poka-yoke or mistake proofing or defect prevention is another common lean element (Gurumurthy \& Kodali, 2009; Jasti \& Kodali, 2016) to ensure that everything is correct and thereby ensures variability reduction (Al-Tahat \& Jalham, 2015). To have a control over the number of defects produced, process capability measurements were considered as an effective lean practice by Shah and Ward (2003). In support of a wider lean strategy, there is the need to increase process capability and attack wasteful bottlenecks (Hines et al., 2004). Process capability studies, along with SPC, provide a powerful route to problem identification and resolution (Thomas et al., 2008). The quality tools and techniques which are commonly considered important for LM implementation are Quality Control Tools (Houshmand \& Jamshidnezhad, 2006), 5 
Why's Root Cause Analysis (Arnheiter \& Maleyeff, 2005; Eswaramoorthi, 2011), Quality Function Deployment (Deflorin \& Scherrer-Rathje, 2012; Singh et al., 2009; Thomas et al., 2008) and Failure Mode and Effect Analysis (Eswaramoorthi, 2011; Mostafa et al., 2015; Vinodh \& Joy 2012). The quality practices enabling LM implementation are 5S concept (Mahapatra \& Mohanty, 2007; Salem et al., 2016), Quality Circles (Jasti \& Kodali, 2015; Karlsson \& Åhlström, 1996, Marin-Garcia \& Bonavia, 2015), Jidoka (Gupta \& Jain, 2013; Liker \& Morgan, 2006), PDCA (plan-do-check-act) cycle (Begam et al., 2013; Salem et al., 2016; Wong et al., 2009) and Kaikaku or instant revolution (Bhasin, 2012; Bhasin \& Burcher, 2006]. TQM, Kaizen, SPC, process capability, quality tools and quality governance may all be considered under the umbrella of Quality Governance. Accordingly, we pose the following hypothesis:

H5. Quality governance (QG) is positively related to successful LM implementation.

Process mapping is a detailed workflow diagram to indicate the manufacturing flow, for clearer and better understanding of a process required to complete a task. This tool assists in getting the metrics for plotting process details (Green et al, 2010) and helps to identify improvements in the process flow (Taylor et al., 2013). Value analysis is a technique to assess the value content of the elements of a product or process and value is what people are willing to pay for (Upadhye et al., 2010). Value analysis is one of the key practices associated with lean (Deflorin \& Scherrer-Rathje, 2012; Jayaram et al., 2008) and lean thinking focuses on the reduction and removal of wastes by value analysis (Bendell, 2006) which has been considered as one of the vital tools and techniques to implement LM system (Upadhye et al., 2010). Value Stream Mapping (VSM) technique is one of the starting tools for applying lean and helps to identify the value in the entire process (Singh et al., 2009). It was used first introduced by Rother and Shook (1999) and supports lean practitioners to identify the problematic areas to be improved. Numerous literatures focus on elimination of wastes as the principal objective of LM (Pettersen, 2009; Shah \& Ward, 2007; Vinodh \& Chintha, 2011). The seven commonly accepted wastes in the Toyota Production System are overproduction, waiting of materials and/or workers, transport, inappropriate processing, unnecessary inventory, unnecessary motion and defects (Hines \& Rich, 1997). Underutilization of employees is recently being considered as the eighth waste (Vinodh \& Chintha, 2011). Visual management, a lean enabler, is one of the foundations of the TPS and is designed to ensure visibility in order to improve the operation of a factory (Bhasin, 2008). This is to be supported by equipment layout and materials handling which has been considered as a key issue to LM by Taj (2005). Shah and Ward (2007) consider equipment layout as one of the key measurement instruments of lean production and to avoid process interruptions, as well as to reduce wastages, plant and equipment layout has been regarded as a dimension of lean systems by Taylor et al. (Taylor et al., 2013). It follows from the aforesaid discussions that strategic process control through process and value stream mapping, value analysis and waste elimination, visual management and equipment layout and materials handling, will facilitate the lean implementation process. This leads us to the following hypothesis:

H6. Strategic process control (SPC) is positively related to successful LM implementation.

Lean metrics are considered as performance measures for tracking the effectiveness of lean implementation (Wan \& Frank Chen, 2008). Among the existing lean metrics, manufacturing cycle efficiency (MCE), an index for cycle time reduction, represents the leanness level in terms of time-based performance (Wan \& Frank Chen, 2008). Shah and Ward (2003) consider JIT, TQM, TPM and HRM as four bundles of lean practices and state that implementing each of the bundles contributes substantially to the operating performance of plants. The proponents of lean advocate that lean has several benefits to offer, namely, shorter cycle and lead times, lower WIP, lower cost, greater production flexibility, higher revenue, higher throughput and increased profit (Bhasin, 2008). The principles of lean manufacturing and the associated tools facilitate the elimination of waste in the production environment, creating a mindset of continuous improvement, leading to reduced cost and improved productivity (Salem et al., 2016). Gupta and Jain (2013) clarify that lean manufacturing can help organizations to cut costs by 
between 15 and $70 \%$, reduce waste by $40 \%$, push productivity up by between 15 and $40 \%$, and decrease space and inventory requirements by $60 \%$. By implementing LM practices, several operational benefits like improvement in upstream, downstream and internal value stream performances have been gained by manufacturing companies (Panizzolo et al., 2012). According to Achanga et al. (2012), desirable outcomes of lean implementation are both tangible and intangible; tangible benefits include reduction of lead-time, lower inventory levels and increased productivity; while intangible benefits include increase in the level of employees' motivation and positive attitude towards change. Improvements in several operational and organizational performance metrics by implementing lean have been enumerated by Chavez et al. (2015). As stated by Bhasin and Burcher (2006), strategic advantage had been generated by the adoption of lean production and the Engineering Employers Federation had "found a clear link between lean manufacturing and higher productivity and profitability." According to MarinGarcia and Bonavia (2015), numerous studies have concluded that applying LM practices enables businesses to improve their performance (Bhasin \& Burcher, 2006). In a nutshell, operational, administrative and strategic improvements are clearly seen from LM implementation (Singh et al., 2009). All such benefits of lean related to an organization's performance may be summarized as satisfaction of organizational goals and the above discussions lead us to formulate the next hypothesis as follows:

H7. Successful LM (SLM) implementation is positively related to organizational goal satisfaction (OGS).

In the lean model, value is the chain of activities that are required to perform in order to produce an end product to be delivered to the customer who should be the driver of the value stream (Singh et al., 2009). The fundamental approach of lean is to maximize customer value (Kajdan, 2008). LM implementation also results in improved flexibility to react to changes, thus reducing the response time to market (Singh et al., 2009). Researchers in LM advocate that lean offers the benefits of faster response time, increased customer responsiveness, better customer services and shorter delivery times (Bhasin, 2008, Wong et al., 2009) by streamlining customer service functions to reduce the waiting time of customers (Ma et al., 2011). By focusing on perfect order fulfillment (Panizzolo et al., 2012), LM implementation leads to reduction in order processing errors (Ma et al., 2011). The above are indicators of customer satisfaction that has been considered as one of the most common benefits of LM by lean experts (Ma et al., 2011; Singh et al., 2009, Sohal et al., 1994). Our last hypothesis is thus proposed as:

H8. Successful LM (SLM) implementation is positively related to customer satisfaction (CS).

\section{Research Methodology}

The objective of this work is to have an empirical study on the comprehensible list of input and output variables related to LM implementation in the Indian manufacturing context. The basic steps of the research methodology, based on the outline provided by Singh Sangwan et al. (2014), are: identification of input and output manifest variables and latent constructs, model proposition and hypotheses development, development of survey instrument, sampling and data collection and model validation (EFA, CFA and SEM). Identification of the input and output manifest variables and latent constructs, thereby proposing the research model and developing the hypotheses have been presented in the last section. This section focuses on the development of the survey instrument, sampling and data collection.

\subsection{Development of Survey Instrument}

An extensive questionnaire covering the input and output manifest variables was developed. The survey questionnaire was divided into three major parts: The first part of the survey questionnaire was designed to capture the personal information and organization profile of the respondent. The second and third parts captured the responses on the input and output manifests. The present study used five-point Likert scale $(1=$ Strongly disagree, $2=$ Disagree, $3=$ Indifferent, $4=$ Agree, $5=$ Strongly agree $)$ to get the responses for each item on the perception about the importance/significance of a manifest variable involved in LM. 


\subsection{Sampling and Data Collection}

The empirical research is focused on lean implementation in the Indian manufacturing sector. The list of manufacturing companies was obtained from Capitaline Plus, one of India's most popular and upto-date databases. The population of interest was all industries with manufacturing facilities in India and having number of employees exceeding 100 (Chavez et al., 2015; Shah \& Ward, 2003). This excluded those involved in agriculture, forestry, fishing and services. An initial list of 454 such manufacturing facilities was formed. Each company was contacted over phone to see their interest to participate in the survey. Executives in the managerial level were considered who were directly involved in the manufacturing process. Subsequently questionnaires were sent and visits were made to collect responses. Multiple responses from the same organization were also considered. A total of 782 respondents were contacted and after three to four follow-up contacts, a total of 467 usable filled-in (complete) questionnaires were received, ignoring 44 questionnaires consisting of missing responses on various manifests. The demographic profile of the sample is presented in Table 3. Non response bias was investigated by comparing early respondents to late respondents, depending on the return date (Fullerton et al., 2014). Very few responses were received after the first contact. We classified early responders $(n=193)$ as those that responded following first two contacts and late responders $(n=274)$ as those who responded after three or four contacts. No statistically significant differences were found between early and late respondents for any of the variables in our research model, implying an absence of non-response bias.

Table 3

Demographic Profile of Respondents

\begin{tabular}{llccc}
\hline Sample characteristic & Number of responses & Classifications & Total & Percent \\
\hline Geographical Area & 467 & India & 467 & 100 \\
Organization Type & 467 & Manufacturing & 467 & 100 \\
\hline & & $0-5$ years & 145 & 31.9 \\
Respondent's years of experience & 454 & $6-10$ ears & 172 & 37.9 \\
& & $>10$ years & 137 & 30.2 \\
\hline & \multirow{2}{*}{465} & Executive & 112 & 24.1 \\
& & Manager & 237 & 51.0 \\
Respondent's profile & & Senior Manager & 82 & 17.6 \\
& \multirow{2}{*}{312} & Head & 34 & 7.3 \\
\hline Firm's no. of employees & & $50-10$ & 143 & 45.8 \\
& & $>100$ & 169 & 54.2 \\
\hline
\end{tabular}

\section{Results and Model Validation}

We examine our hypotheses using a structural equation model (Figure 1) populated with survey data from 467 responses from the Indian manufacturing sector.

\subsection{Content Validity}

The comprehensive list of manifest variables was developed using extensive literature survey, based on which, initially 30 input manifest variables and 13 output manifest variables were identified through a Delphi exercise with seven practitioners and researchers known for their knowledge and experience in LM implementation. Further, to assess content validity, a panel of experts from industry and academics was requested to go through the questionnaire. Their remarks and suggestions were taken into consideration and several questions were rephrased and modified in the final instrument to receive meaningful responses.

\subsection{Exploratory Factor Analysis (EFA)}

A principal-components-based EFA was conducted on both input and output manifests to develop a parsimonious representation for the various constructs in the survey (Fullerton et al., 2014), to rule out variables not appropriately related to the constructs (Moori et al., 2013) and to reduce and summarize 
the data (Fullerton \& Wempe, 2009). Factors were extracted using maximum likelihood method followed by varimax rotation. Kaiser criterion (Eigen values $>1$ ) was employed to extract factors. For all items to contribute well to the represented factors, the minimum factor loading value of 0.45 was considered (Hair et al., 2009). The results indicate that 26 items could be identified as input manifest variables as compared to original 30 items. No item was eliminated out of the output manifests. The same 6 input factors or latent constructs (with Eigen values $>1$ ) emerged from the input manifests and 3 output factors or latent constructs (with Eigen values $>1$ ) emerged from the output manifests. Moreover, according to Podsakoff et al. (2003, p. 889), if a "substantial amount of common method bias is present, either (a) a single factor will emerge from the factor analysis, or (b) one general factor will account for the majority of the covariance among measures." In this analysis, only $9.4 \%$ of the variance was explained by the first factor in case of input factors and $27.2 \%$ of the variance was explained by the first factor in case of output factors. Hence, it may be concluded that that the level of common method bias that may exist in the data is low and not of significant concern.

EFA alone is not sufficient to assess all the essential measurement properties of the constructs (Singh Sangwan et al., 2014). There are two measurement models which are to be evaluated - a measurement model for the input constructs and another measurement model for the output constructs. Each of these measurement models are evaluated with a confirmatory factor analysis (CFA) and then the full model is evaluated using a structural equation model (SEM). This two-step modeling approach was recommended by Schumacker and Lomax (1996) and was also followed by Fullerton et al. (2014). Results of EFA and SEM are discussed in the following two sections. The measurement model assesses the convergent validity and discriminant validity, and the full model is used for the assessment of predictive validity (Fullerton et al., 2014). To test both the measurement model and structural model, the maximum likelihood approach in AMOS 21 was used.

\subsection{Confirmatory Factor Analysis (CFA)}

Results from CFA for individual manifests are indicated in Table 4. The t-values are all significant to $\mathrm{p}<0.000$. The factor/latent correlation matrix (Table 5) indicates that the factors are positively and significantly correlated with one other. Construct validity is assessed by both convergent and discriminant validity (Ghobakhloo \& Hong, 2014).

Convergent validity is found to be adequate because AVE (Average Variance Explained) of all variables are significantly greater than 0.5 (Fornell \& Larcker, 1981). For satisfactory discriminant validity, a construct is considered to be distinct from other constructs if the square root of the AVE for it is greater than its correlations with other latent constructs (Barclay et al., 1995). The square root values of the AVE for each construct are indicated on the diagonal of Table 5 in boldface and are found to be larger than the correlation of that construct with all other constructs in the model. Hence the results satisfy the discriminant validity. Cronbach's $\alpha$-coefficients are used to test internal consistency or reliability of each construct (Cronbach, 1951) and the acceptable standard of Cronbach's $\alpha$-coefficient is 0.70 (Nunnally, 1978). Since, all the $\alpha$-coefficients have values more than 0.7 (Table 4 ), they are acceptable. However, Cronbach's $\alpha$ assumes equally weighted measures. Hence, the composite reliability values (they do not assume equal weighted measures) are also assessed (Table 4) and are found to be above the acceptable standard of 0.7 (Fornell \& Larcker, 1981). 
Table 4

Results from CFA

\begin{tabular}{|c|c|c|c|c|c|c|}
\hline $\begin{array}{c}\text { Latent } \\
\text { Constructs }\end{array}$ & $\begin{array}{l}\text { Manifest } \\
\text { Variables }\end{array}$ & $\begin{array}{c}\text { Standardized } \\
\text { Coefficients } \\
\text { (Loadings) }\end{array}$ & $\mathrm{t}$ values & $\begin{array}{c}\text { Cronbach's } \\
\text { Alpha }\end{array}$ & C.R. & AVE \\
\hline \multirow[t]{5}{*}{ HRM } & HRM1 & 0.761 & a & 0.833 & 0.817 & 0.592 \\
\hline & HRM2 & 0.715 & 9.426 & & & \\
\hline & HRM3 & 0.861 & 9.290 & & & \\
\hline & HRM4 & 0.833 & 9.149 & & & \\
\hline & HRM5 & 0.850 & 10.141 & & & \\
\hline \multirow[t]{4}{*}{ IPS } & IPS1 & 0.766 & $\mathrm{a}$ & 0.829 & 0.857 & 0.634 \\
\hline & IPS2 & 0.895 & $9 . \overline{4} 40$ & & & \\
\hline & IPS3 & 0.730 & 9.606 & & & \\
\hline & IPS4 & 0.875 & 9.824 & & & \\
\hline \multirow[t]{5}{*}{ IOS } & IOS1 & 0.737 & a & 0.810 & 0.834 & 0.627 \\
\hline & IOS2 & 0.817 & 10.081 & & & \\
\hline & IOS3 & 0.874 & 9.341 & & & \\
\hline & IOS4 & 0.894 & 10.035 & & & \\
\hline & IOS5 & 0.799 & 9.223 & & & \\
\hline \multirow[t]{4}{*}{ MR } & MR1 & 0.720 & a & 0.832 & 0.827 & 0.584 \\
\hline & MR2 & 0.784 & 9.404 & & & \\
\hline & MR3 & 0.744 & 10.173 & & & \\
\hline & MR4 & 0.762 & 9.989 & & & \\
\hline \multirow[t]{4}{*}{ QG } & QG1 & 0.842 & a & 0.856 & 0.874 & 0.633 \\
\hline & QG2 & 0.812 & 9.265 & & & \\
\hline & QG3 & 0.785 & 10.232 & & & \\
\hline & QG4 & 0.794 & 9.684 & & & \\
\hline \multirow[t]{4}{*}{ SPC } & SPC1 & 0.794 & a & 0.848 & 0.869 & 0.626 \\
\hline & SPC2 & 0.784 & 9.235 & & & \\
\hline & SPC3 & 0.778 & 9.322 & & & \\
\hline & SPC4 & 0.836 & 9.287 & & & \\
\hline \multirow[t]{6}{*}{ SLM } & SLM1 & 0.789 & ${ }^{\mathrm{a}}$ & 0.869 & 0.905 & 0.659 \\
\hline & SLM2 & 0.767 & 10.086 & & & \\
\hline & SLM3 & 0.721 & 10.128 & & & \\
\hline & SLM4 & 0.759 & 9.737 & & & \\
\hline & SLM5 & 0.775 & 10.137 & & & \\
\hline & SLM6 & 0.862 & 9.839 & & & \\
\hline \multirow[t]{3}{*}{ OGS } & OGS1 & 0.843 & ${ }_{-}^{\mathrm{a}}$ & 0.831 & 0.854 & 0.615 \\
\hline & OGS2 & 0.887 & 9.361 & & & \\
\hline & OGS3 & 0.732 & 9.986 & & & \\
\hline \multirow[t]{4}{*}{$\mathrm{CS}$} & CS1 & 0.722 & ${ }^{\mathrm{a}}$ & 0.847 & 0.849 & 0.608 \\
\hline & CS2 & 0.729 & 9.897 & & & \\
\hline & CS3 & 0.762 & 9.934 & & & \\
\hline & CS4 & 0.854 & 9.655 & & & \\
\hline
\end{tabular}

Notes:

- $\mathrm{n}=467$

- Refer Tables I and II for description of the latent constructs and manifest variables

- Measurement models are estimated using maximum likelihood.

- a indicates a parameter that was fixed at 1.0

- $t$-values: all significant to $p<0.000$ 
Table 5

Correlations Table

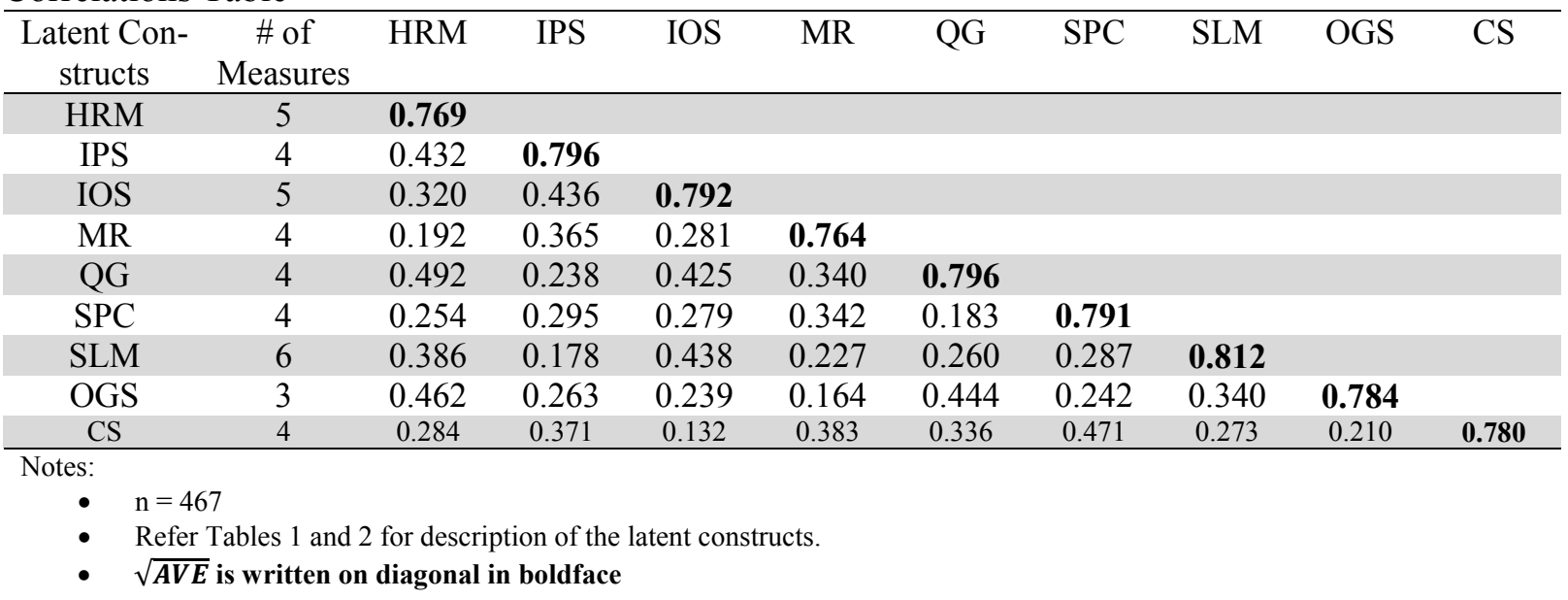

\subsection{Structural Equation Modelling (SEM)}

Table 6 and Fig. 1 exhibit the results of the structural model. Before the path coefficients can be assessed, we evaluate the fitness of the structural equation model. The ratio of $\chi^{2}$ to degrees of freedom is found to be 1.822, indicating an acceptable fit (Kline, 2015). Value of RMSEA is 0.030 which is much less than the acceptable upper limit of 0.08 (Browne \& Cudeck, 1992). The remaining fit indices indicated in Table 6 (GFI, AGFI, NFI, CFI) exceed the acceptable fit level of 0.8 (Hair et al., 2009) and PGFI and PNFI exceed the acceptable fit level of 0.5 (Kaynak, 2003). Hence the goodness of fit statistics generally indicate a good fit to the data. The path coefficients or loadings indicate the strengths of the relationships between the endogenous and exogenous variables and the t-value of each path indicates whether the hypothesis is supported or not by the empirical data.

Table 6

Results of Structural Equation Modelling

\begin{tabular}{cccccc}
\hline $\begin{array}{c}\text { Path / Structural } \\
\text { Relationships }\end{array}$ & Hypotheses & $\begin{array}{c}\text { Standardized } \\
\text { Coefficient }\end{array}$ & t-Values & Significance & Decision \\
\hline HRM $\rightarrow$ SLM & H1 & 0.288 & 3.816 & $* * *$ & Supported \\
IPS $\rightarrow$ SLM & H2 & 0.523 & 5.732 & $* * *$ & Supported \\
IOS $\rightarrow$ SLM & H3 & 0.487 & 5.553 & $* * *$ & Supported \\
MR $\rightarrow$ SLM & H4 & 0.343 & 4.208 & $* * *$ & Supported \\
QG $\rightarrow$ SLM & H5 & 0.354 & 4.231 & $* * *$ & Supported \\
SPC $\rightarrow$ SLM & H6 & 0.262 & 3.655 & $* *$ & Supported \\
SLM $\rightarrow$ OGS & H7 & 0.325 & 3.934 & $* * *$ & Supported \\
SLM $\rightarrow$ CS & H8 & 0.432 & 4.891 & $* * *$ & Supported \\
\hline
\end{tabular}

Notes:

- $\mathrm{n}=467$

- $\quad * * *$ and $* *$ indicate the significance at $\mathrm{p}$ value at $<0.01,0.05$ respectively

- Model Fit Indices: Ratio of $\chi^{2}$ to degrees of freedom $=1.822$, RMSEA $=0.030, \mathrm{GFI}=0.921, \mathrm{AGFI}=0.910$, $\mathrm{NFI}=0.931, \mathrm{CFI}=0.955, \mathrm{PGFI}=0.783, \mathrm{PNFI}=0.818$.

\section{Discussion}

The lean implementation model, discussed above, is expected to be very useful to the lean practitioners. It helps to integrate HR with the internal processes into a unified coherent complete manufacturing 
system; LM implementation entails optimization of the manufacturing process to satisfy both customer requirements and organizational goals. On one hand, this model attempts to frame an exhaustive list of all the human inputs and inputs related to internal practices (Table 1) for LM implementation. On the other hand the output manifests (Table 2) for successful LM implementation will guide the lean implementer to assess the effect of implementation.

Human resources of an organization are the primary drivers of LM implementation. Empowerment of workforce (So \& Sun, 2011) coupled with high level of effective leadership (Ravikumar et al., 2013) helps in higher lean implementation. To ensure successful LM implementation, an organization needs to have a flexible cross-functional work force, a job-rotation program, and needs to have a formal, cross-functional training program in place (Shah \& Ward, 2003). Teamwork and team management for decision making are important in lean efforts, particularly because they provide knowledge sharing opportunities (Pakdil \& Leonard, 2014; Vinodh \& Chintha, 2011; Vinodh \&Joy, 2012). Our present study also supports the importance of Human Relations Management (hypothesis H1) in lean implementation since HRM is found to be positively related to successful LM implementation (coef. $=0.288$, $\mathrm{p}<0.01)$.

Sequence of activities and operations needs to be planned to obtain a true linear seamless flow; planning and scheduling actions are essential for continued commitment to improvement. Cycle time reduction has been considered as one of the categories of lean thinking methods or culture that leads to successful lean manufacturing implementation (Shetty et al., 2010). Implementation of reduction of cycle time and lead time as lean practices helps to improve productivity (Nepal et al., 2011). Lean practices and techniques focus on streamlining processes (Shah et al., 2008; Vinodh \& Chintha, 2011) to minimise variations and thereby to facilitate cost reduction (Vinodh \& Joy, 2012) and improve operational performance (Alsmadi et al., 2012). Our current research supports the significance of the integrated nature of planning and scheduling (hypothesis $\mathrm{H} 2$ ) as the standardized coefficient of Integrative Planning and Scheduling (IPS) is quite high and the hypothesis is strongly supported (coef. $=0.523, \mathrm{p}<0.01$ ).

The Toyota Production System was based around the desire to produce in a continuous flow. Zahraee (2016) expressed that continuous flow is a crucial lean tool for lean manufacturing implementation. Continuous flow is one of the lean practices that encompass a wide variety of shop floor manufacturing initiatives (Shah et al., 2008). The pull system regulates the flows on the factory floor driven by demand from downstream that pulls production upstream. Reduction in setup time (Serrano Lasa et al., 2009; Vinodh \& Chintha, 2011) and lot size assist in the LM implementation process. In the process, TPM attempts to eliminate any losses in equipment and production efficiency through active team-based participation (Cullinane et al., 2014; Mostafa et al., 2015). Thus we have enough evidence in past literature that a proper harmonization of internal operations is required to maintain the flow, the heartbeat of lean production (Bevilacqua et al., 2015; Cullinane et al., 2014). The hypothesis (H3) in the present study that Internal Operations Synchronization (IOS) is positively related to successful LM implementation is supported (coef. $=0.487, \mathrm{p}<0.01$ ) and thus complements past literature.

According to Liker and Morgan (2006), management decisions should be based on a long-term philosophy, even at the expense of short-term financial goals. Undeniably, lean requires a long-term commitment of the management (Bhasin \& Burcher, 2006; So \& Sun, 2011). The results of our research also support the hypothesis (H4) that Management Role (MR) (hypothesis H4) is positively related to successful LM implementation (coef. $=0.343, p<0.01$ ). The findings of this research complement past research that senior management is not only critical for lean (Motwani, 2003) but also provides the foundation for the implementation of LM (Upadhye et al., 2010).

According to lean protagonists, Quality tools, techniques and practices are the pillars of the LM implementation. TQM, Kaizen, Statistical Process Control and other Quality tools or practices are considered as enablers of LM by many researchers (Al-Tahat \& Jalham, 2015; Susilawati et al, 2015; Vinodh \& 
Chintha, 2011). Results of our study are also in conjunction with this view of lean experts and the hypothesis (H5) that Quality Governance (QG) positively affects successful LM implementation is strongly supported (coef. $=0.354, \mathrm{p}<0.01)$.

Process mapping exercise has been considered as a fundamental technical requirement to be practiced by companies for LM implementation (Bhasin \& Burcher, 2006;, Bhasin, 2012) and the creation of the Value Stream Map is by itself a value adding process as it helps to have more details and deeper insights of the process (McDonald, 2002). Value analysis is one of the key practices associated with lean (Deflorin \& Scherrer-Rathje, 2012; Jayaram et al., 2008) and lean thinking focuses on the reduction and removal of wastes by value analysis (Bendell, 2006) which has been considered as one of the vital tools and techniques to implement LM system (Upadhye et al., 2010). The findings of this research (coef. $=0.262, \mathrm{p}<0.05$ ) provide empirical support for the argument (hypothesis H6) that successful LM implementation is impacted directly by the latent construct, Strategic Process Control (SPC).

Past research indicates that implementation of LM contributes substantially to the operating performance of the firm (Achanga et al., 2012; Alsmadi et al, 2012; Bhasin, 2008; Chavez et al., 2015; Gupta \&Jain, 2013; Jayaram et al., 2008; Panizzolo et al., 2012; Shah \&Ward, 2003) and to customer satisfaction (Bhasin, 2008, Singh et al., 2009). In our research also, both the hypotheses (H7and H8) that successful LM implementation positively affect satisfaction of organization goals (coef. $=0.325$, $\mathrm{p}<0.01$ ) and customer satisfaction (coef. $=0.432, \mathrm{p}<0.01$ ) are strongly supported by the data.

An important and novel contribution of this study is that it focuses on an integrative perspective for implementation of leanness. The four constructs related to the internal practices (namely, IPS, IOS, QG and SPC), which have emerged from our analysis need to be addressed in conjunction with the the HR constructs (HRM amd MR) for successful LM implementation. Role of employees and top management are to be integrated with the internal lean practices towards a systemic development to satisfy the demand of the market without sacrificing organizational goals. All the input latent constructs have their respective contributions, and the more integrative the process is, the better will be the implementation of LM. The latent output constructs, namely, organizational goals satisfaction and customer satisfaction will ultimately help to decide whether the organization has been able to reach its stage of self-actualization in the long-term.

\section{Conclusion}

A comprehensive study of the input manifest variables related to HR and internal processes, along with the output manifest variables for successful lean implementation has been focussed upon in this work. Though lot of work has been done on LM, very few are available on such a comprehensive study of both input parameters, as well as the benefits of LM implementation. Over the last couple of decades, many researchers have put forward many factors responsible for LM implementation but a collation of all such possible factors comprehensively have not been reported. This work is an attempt to bridge this gap in a manufacturing setup. Based on literature survey, followed by Delphi exercise, a structural model is suggested for administering lean implementation. The model suggested in this study, based on the list of manifests, may be treated as a guide for successful LM implementation in a manufacturing enterprise. The model thus conceptualized is then validated with the use of appropriate statistical tools with the help of empirical data from the Indian manufacturing sector.

Certain limitations of this work confine the interpretation of our findings. This study is limited to the manufacturing sector and has scope for extending the concept to the service sector as well. Finally, survey studies with a larger sample size (considering the total number of variables involved) and a larger cross-sectional random sample may provide better understanding of the results found in this study. 


\section{References}

Abdulmalek, F. A., \& Rajgopal, J. (2007). Analyzing the benefits of lean manufacturing and value stream mapping via simulation: A process sector case study. International Journal of production economics, 107(1), 223-236.

Abdulmalek, F. A., Rajgopal, J., \& Needy, K. L. (2006). A classification scheme for the process industry to guide the implementation of lean. Engineering Management Journal, 18(2), 15-25.

Achanga, P., Shehab, E., Roy, R., \& Nelder, G. (2012). A fuzzy-logic advisory system for lean manufacturing within SMEs. International Journal of Computer Integrated Manufacturing, 25(9), 839-852.

Almomani, M. A., Aladeemy, M., Abdelhadi, A., \& Mumani, A. (2013). A proposed approach for setup time reduction through integrating conventional SMED method with multiple criteria decision-making techniques. Computers \& Industrial Engineering, 66(2), 461-469.

Alsmadi, M., Almani, A., \& Jerisat, R. (2012). A comparative analysis of Lean practices and performance in the UK manufacturing and service sector firms. Total Quality Management \& Business Excellence, 23(3-4), 381-396.

Al-Tahat, M. D., \& Jalham, I. S. (2015). A structural equation model and a statistical investigation of lean-based quality and productivity improvement. Journal of Intelligent Manufacturing, 26(3), 571-583.

Arnheiter, E. D., \& Maleyeff, J. (2005). The integration of lean management and Six Sigma. The TQM magazine, 17(1), 5-18.

Barclay, D., Higgins, C., \& Thompson, R. (1995). The partial least squares (PLS) approach to causal modeling: Personal computer adoption and use as an illustration. Technology Studies, 2 (2), 285-309.

Begam, M. S., Swamynathan, R., \& Sekkizhar, J. (2013). Current trends on lean management-A review. International Journal of lean thinking, 4(2), 15-21.

Bendell, T. (2006). A review and comparison of six sigma and the lean organisations. The TQM magazine, 18(3), 255-262.

Bevilacqua, M., Ciarapica, F. E., \& Paciarotti, C. (2015). Implementing lean information management: the case study of an automotive company. Production Planning \& Control, 26(10), 753-768.

Bhamu, J., \& Singh Sangwan, K. (2014). Lean manufacturing: literature review and research issues. International Journal of Operations \& Production Management, 34(7), 876-940.

Bhasin, S. (2008). Lean and performance measurement. Journal of Manufacturing Technology Management, 19(5), 670-684.

Bhasin, S. (2012). Performance of Lean in large organizations. Journal of Manufacturing Systems, 31 (3), 349-357.

Bhasin, S., \& Burcher, P. (2006). Lean viewed as a philosophy. Journal of Manufacturing Technology Management, 17(1), 56-72.

Browne, M.W., \& Cudeck, R. (1992). Alternative ways of assessing model fit. Sociological Methods and Research, 21(2), 230-258.

Chavez, R., Yu, W., Jacobs, M., Fynes, B., Wiengarten, F., \& Lecuna, A. (2015). Internal lean practices and performance: The role of technological turbulence. International Journal of Production Economics, 160, 157-171.

Cronbach, L.J. (1951). Coefficient alpha and the internal structure of tests. Psychometrika, 16(3), 297-334.

Cullinane, S.J., Bosak, J., Flood, P.C., \& Demerouti, E. (2014). Job design under lean manufacturing and the quality of working life: a job demands and resources perspective. The International Journal of Human Resource Management, 25(21), 2996-3015.

Deflorin, P., \& Scherrer-Rathje, M. (2012). Challenges in the transformation to lean production from different manufacturing-process choices: a path-dependent perspective. International Journal of Production Research, 50(14), 3956-3973.

Doolen, T.L., \& Hacker, M.E. (2005). A review of lean assessment in organizations: an exploratory study of lean practices by electronics manufacturers. Journal of Manufacturing Systems, 24(1), 55-67.

Eswaramoorthi, M., Kathiresan, G.R., Prasad, P.S.S., \& Mohanram, P.V. (2011). A survey on lean practices in Indian machine tool industries. The International Journal of Advanced Manufacturing Technology, 52(9-12), 1091-1101.

Fornell, C., \& Larcker, D.F. (1981). Evaluating structural equation models with unobservable variables and measurement error. Journal of Marketing Research, 18, 39-50.

Forza, C. (1996). Work organization in lean production and traditional plants: what are the differences?. International Journal of Operations and Production Management, 16(2), 42-62.

Fullerton, R.R., \& Wempe, W.F. (2009). Lean manufacturing, non-financial performance measures, and financial performance. International Journal of Operations and Production Management, 29 (3), 214-240.

Fullerton, R.R., Kennedy, F.A., \& Widener, S.K. (2014). Lean manufacturing and firm performance: The incremental contribution of lean management accounting practices. Journal of Operations Management, 32(7), 414-428.

Ghobakhloo, M., \& Hong, T.S., (2014). IT investments and business performance improvement: the mediating role of lean manufacturing implementation. International Journal of Production Research, 52(18), 5367-5384.

Green, J.C., Lee, J., \& Kozman, T.A. (2010). Managing lean manufacturing in material handling operations. International Journal of Production Research, 48(10), 2975-2993. 
Gupta, S., \& Jain, S.K. (2013). A literature review of lean manufacturing. International Journal of Management Science and Engineering Management, 8(4), 241-249.

Gurumurthy, A., \& Kodali, R. (2009). Application of benchmarking for assessing the lean manufacturing implementation. Benchmarking: An International Journal, 16(2), 274-308.

Hair, J., Black, W.C., Babin, B.J., \& Anderson, R.E. (2009). Multivariate Data Analysis, $7^{\text {th }}$ ed. Pearson Education Ltd., UK.

Haque, B., \& James-Moore, M. (2014). Applying lean thinking to new product introduction. Journal of Engineering Design, 15 (1), 1-31.

Hines, P., \& Rich, N. (1997). The seven value stream mapping tools. International Journal of Operations and Production Management, 17(1), 46-64.

Hines, P., Holweg, M., \& Rich N. (2004). Learning to evolve: a review of contemporary lean thinking. International Journal of Operations \& Production Management, 24(10), 994-1011.

Holweg, M. (2007). The genealogy of lean production. Journal of Operations Management, 25(2), 420-437.

Houshmand, M., \& Jamshidnezhad, B. (2006). An extended model of design process of lean production systems by means of process variables. Robotics and Computer-Integrated Manufacturing, 22(1), 1-16.

Kajdan, V. (2008). Bumpy road to lean enterprise. Total Quality Management, 19(1-2), 91-99.

Karlsson, C., \& Åhlström, P. (1996). Assessing changes towards lean production. International Journal of Operations and Production Management, 16(2), 24-41.

Kaynak, H. (2003). The relationship between total quality management practices and their effects on firm performance. Journal of Operations Management, 21(4), 405-435.

Kline, R.B. (2015). Principles and Practice of Structural Equation Modeling, $4^{\text {th }}$ ed. Guildford Press, New York, NY.

Krafcik, J.F. (1988). Triumph of the lean production system. MIT Sloan Management Review, 30(1), 41-52.

Lean Manufacturing Competitiveness Scheme 2013, available at: http://www.lmcs.npcindia.org.in/guidelines.php/ (accessed 14 April 2015).

Liker, J.K., \& Morgan, J.M. (2006). The Toyota way in services: the case of lean product development. The Academy of Management Perspectives, 20(2), 5-20.

Ma, J., Wang, K., \& Xu, L. (2011). Modelling and analysis of workflow for lean supply chains. Enterprise Information Systems, 5(4), 423-447.

Mahapatra, S.S., \& Mohanty, S.R. (2007). Lean manufacturing in continuous process industry: an empirical study. Journal of Scientific and Industrial Research, 66, 19-27.

Marin-Garcia, J.A., \& Bonavia, T. (2015). Relationship between employee involvement and lean manufacturing and its effect on performance in a rigid continuous process industry. International Journal of Production Research, 53(11), 3260-3275.

McDonald, T., Van Aken, E.M., \& Rentes, A.F. (2002). Utilising simulation to enhance value stream mapping: a manufacturing case application. International Journal of Logistics, 5(2), 213-232.

Moori, R.G., Pescarmona, A., \& Kimura, H. (2013). Lean Manufacturing and Business Performance in Brazilian Firms. Journal of Operations and Supply Chain Management, 6(1), 91-105.

Mostafa, S., Lee, S.H., Dumrak, J., Chileshe, N., \& Soltan, H. (2015). Lean thinking for a maintenance process. Production \& Manufacturing Research, 3(1), 236-272.

Motwani, J. (2003). A business process change framework for examining lean manufacturing: a case study. Industrial Management \& Data Systems, 103(5), 339-346.

Näslund, D. (2008). Lean, six sigma and lean sigma: fads or real process improvement methods?. Business Process Management Journal, 14(3), 269-287.

National Manufacturing Policy 2011, available at:

http://www.dinic.in/sites/default/files/po-ann4.pdf/ (accessed 10 February 2015).

Nepal, B.P., Yadav, O.P., \& Solanki, R. (2011). Improving the NPD process by applying lean principles: A case study. Engineering Management Journal, 23(1), 52-68.

Nunnally, J. (1978). Psychometric Theory, 2nd Edition. McGraw-Hill, New York, NY.

Pakdil, F., \& Leonard, K.M. (2014). Criteria for a lean organisation: development of a lean assessment tool. International Journal of Production Research, 52(15), 4587-4607.

Panizzolo, R., Garengo, P., Sharma, M.K., \& Gore, A. (2010). Lean manufacturing in developing countries: evidence from Indian SMEs. Production Planning \& Control, 23(10-11), 769-788.

Pettersen, J. (2009). Defining lean production: some conceptual and practical issues. The TQM Journal, 21(2), 127142.

Piercy, N., \& Rich, N. (2009). The implications of lean operations for sales strategy: from sales-force to marketingforce. Journal of Strategic Marketing, 17(3-4), 237-255.

Podsakoff, P.M., MacKenzie, S.B., Lee, J.Y., \& Podsakoff, N.P. (2003). Common method biases in behavioral research: a critical review of the literature and recommended remedies. Journal of Applied Psychology, 88(5), 879903. 
Ravikumar, M.M., Marimuthu, K., Parthiban, P., Abdul \& Zubar, H. (2013). Leanness Evaluation in 6 Manufacturing MSME's using AHP and SEM Techniques. International Journal of Mechanical and Mechatronics Engineering, 13(06), 29-36.

Rother, M., \& Shook, J. (1999). Learning to See - Value Stream Mapping to Add Value and Eliminate Waste, Lean Enterprise Institute Inc., Brookline, MA, USA.

Salem, R., Musharavati, F., Hamouda, A.M., \& Al-Khalifa, K.N. (2016). An empirical study on lean awareness and potential for lean implementations in Qatar industries. The International Journal of Advanced Manufacturing Technology, 82(9-12), 1607-1625.

Schumacker, R.E., \& Lomax, R.G. (1996). A Beginner's Guide to Structural Equation Effects in Structural Equation Modeling. Erlbaum, Mahwah, NJ.

Serrano Lasa, I., Castro, R.D., \& Laburu, C.O. (2009). Extent of the use of Lean concepts proposed for a value stream mapping application. Production Planning \& Control, 20(1). 82-98.

Shah, R., \& Ward, P.T. (2003). Lean manufacturing: context, practice bundles, and performance. Journal of Operations Management, 21(2), 129-149.

Shah, R., \& Ward, P.T. (2007). Defining and developing measures of lean production. Journal of Operations Management, 25(4), 785-805.

Shah, R., Chandrasekaran, A., \& Linderman, K. (2008). In pursuit of implementation patterns: the context of Lean and Six Sigma. International Journal of Production Research, 46(23), 6679-6699.

Shetty, D., Ali, A., \& Cummings, R. (2010). Survey-based spreadsheet model on lean implementation. International Journal of Lean Six Sigma, 1(4), 310-334.

Singh Sangwan, K., Bhamu, J., \& Mehta, D. (2014). Development of lean manufacturing implementation drivers for Indian ceramic industry. International Journal of Productivity and Performance Management, 63(5), 569-587.

Singh, B., Garg, S.K., \& Sharma, S.K. (2009). Lean can be a survival strategy during recessionary times. International Journal of Productivity and Performance Management, 58(8), 803-808.

So, S., \& Sun, H. (2011). An extension of IDT in examining the relationship between electronic-enabled supply chain integration and the adoption of lean production. International Journal of Production Research, 49(2), 447-466.

Sohal, A.S., \& Egglestone, A. (1994). Lean production: experience among Australian organizations. International Journal of Operations and Production Management, 14(11), 35-51.

Susilawati, A., Tan, J., Bell, D., \& Sarwar, M. (2015). Fuzzy logic based method to measure degree of lean activity in manufacturing industry. Journal of Manufacturing Systems, 34, 1-11.

Taj, S. (2005). Applying lean assessment tools in Chinese hi-tech industries. Management Decision, 43(4), 628-643.

Taylor, A., Taylor., M., \& McSweeney, A. (2013). Towards greater understanding of success and survival of lean systems. International Journal of Production Research, 51(22), 6607-6630.

Thomas, A., Barton, R., \& Chuke-Okafor C (2008). Applying lean six sigma in a small engineering company-a model for change. Journal of Manufacturing Technology Management, 20(1), 113-29.

Upadhye, N., Deshmukh, S.G., \& Garg, S. (2010). Lean manufacturing system for medium size manufacturing enterprises: an Indian case. International Journal of Management Science and Engineering Management, 5(5), 362-375.

Vinodh, S., \& Chintha, S.K. (2011). Leanness assessment using multi-grade fuzzy approach. International Journal of Production Research, 49(2), 431-445.

Vinodh, S., \& Joy, D. (2012). Structural equation modelling of lean manufacturing practices. International Journal of Production Research, 50(6), 1598-1607.

Wan, H.D., \& Frank Chen, F. (2008). A leanness measure of manufacturing systems for quantifying impacts of lean initiatives. International Journal of Production Research, 46(23), 6567-6584.

Womack, J.P., Jones, D.T., Roos, D., \& Carpenter, D.S. (1990). The machine that changed the world. Rawson Associates, Macmillan Publishing Company, New York, NY.

Wong, Y.C., Wong. K.Y., \& Ali A. (2009). A study on lean manufacturing implementation in the Malaysian electrical and electronics industry. European Journal of Scientific Research, 8(4). 521-535.

Zahraee, S.M. (2016). A survey on lean manufacturing implementation in a selected manufacturing industry in Iran. International Journal of Lean Six Sigma, 7(2), 136-48.

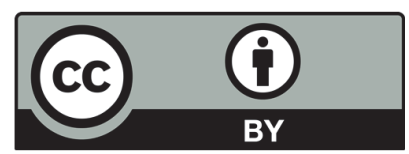

(C) 2017 by the authors; licensee Growing Science, Canada. This is an open access article distributed under the terms and conditions of the Creative Commons Attribution (CC-BY) license (http://creativecommons.org/licenses/by/4.0/). 